\title{
Point cloud processing techniques and image analysis comparisons for boat shapes measurements
}

\author{
Sofia Catalucci ${ }^{1,2}$, Roberto Marsili $^{1}$, Michele Moretti ${ }^{1}$, Gianluca Rossi $^{1}$ \\ ${ }^{1}$ Università degli Studi di Perugia, Dipartimento d'Ingegneria, Via Goffredo Duranti 93, 06125 Perugia, Italy \\ ${ }^{2}$ Present address: University of Nottingham, Advanced Manufacturing Building, Jubilee Campus, NG81BB Nottingham, United Kingdom
}

\begin{abstract}
Photomodelling is a new and fast solution for 3D modelling, based on the same principles of photogrammetry. The comparison between photomodelling and the metrological technique of structured light 3D scanning, provided by the Creaform Go Scan 50 with metrological certification, is the aim of this paper, defining performances and verifying the potential of this innovative, simple and economical technique.
\end{abstract}

\section{Section: RESEARCH PAPER}

Keywords: photomodelling; metrology; point clouds; Iterative Closest Point algorithm

Citation: Sofia Catalucci, Roberto Marsili, Michele Moretti, Gianluca Rossi, Point cloud processing techniques and image analysis comparisons for boat shapes measurements, Acta IMEKO, vol. 7, no. 2, article 7, June 2018, identifier: IMEKO-ACTA-07 (2018)-02-07

Section Editor: Fabio Leccese, Università degli Studi di Roma Tre, Italy

Received January 17, 2018; In final form March 25, 2018; Published June 2018

Copyright: @ 2018 IMEKO. This is an open-access article distributed under the terms of the Creative Commons Attribution 3.0 License, which permits unrestricted use, distribution, and reproduction in any medium, provided the original author and source are credited

Funding: This work was supported by the Engineering Department, Università degli Studi di Perugia, Italy

Corresponding author: Sofia Catalucci, e-mail: sofia.catalucci@gmail.com

\section{INTRODUCTION}

The design and modelling of a boat involve complex freeform geometric shapes, difficult to measure and survey with traditional metrology methods. Scan data allow creating precise 3D models that can be used by naval designers and engineers to ensure the quality of interior and exterior construction, as well as for simulation and inspection purposes.

For this purpose, the paper describes photomodelling technique, a recent and fast image processing and alignment method that leads to the reconstruction of three-dimensional models, starting from the simple acquisition of photographic images. Close to photogrammetry, the result obtained is a $3 \mathrm{D}$ point cloud, a set of $x, y, z$ space coordinates, first form of the object surveyed [1].

A point cloud can be identified as a pixel cloud, because of the direct relationship between photomodelling and photography: each pixel of an image corresponds to a point of the cloud, thus preserving the chromatic characteristics of the object surveyed [2]-[6].

\section{TEST PERFORMED}

Object of the survey is a Beneteau First 456/s boat (Figure 1), 1984, with 3 cabin all with toilets, engine Yanmar $55 \mathrm{cv}, 14$

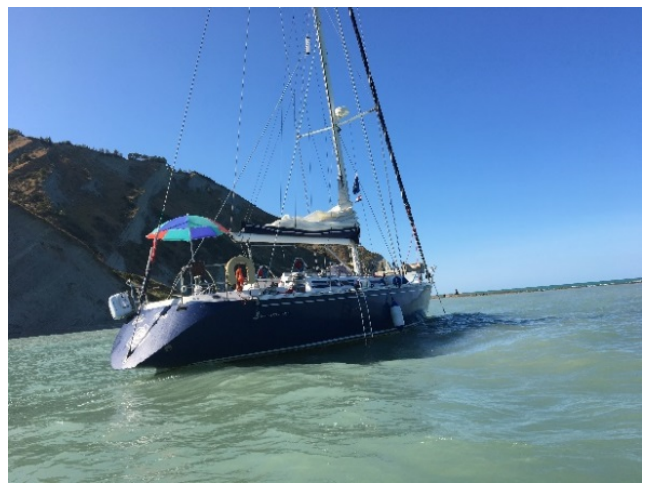

Figure 1. The Boat.

$\mathrm{m}$ length. The measurements have been performed on the driving seat area, by using photomodelling technique and the Creaform 3D scanner, placed on the same surface (Figure 2).

At first, the survey has been performed using the $3 \mathrm{D}$ scanning system (Figure 3); target stickers have been applied randomly to facilitate the capture process, due to the auto similarity of the surface pattern. 


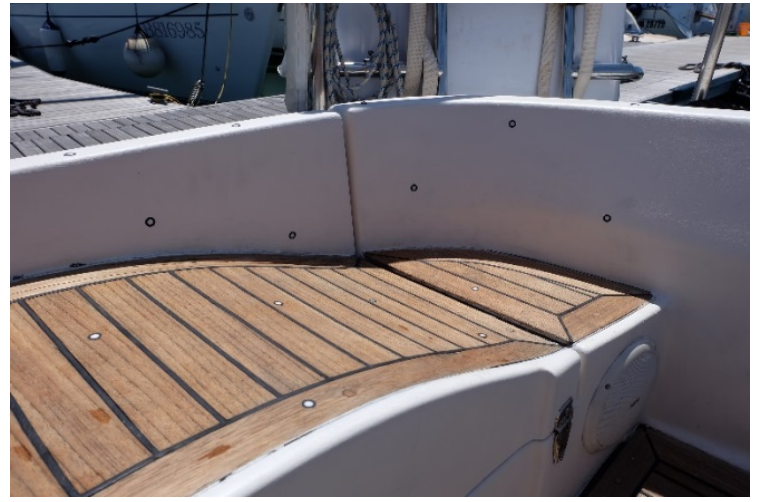

Figure 2. Driving seat area.
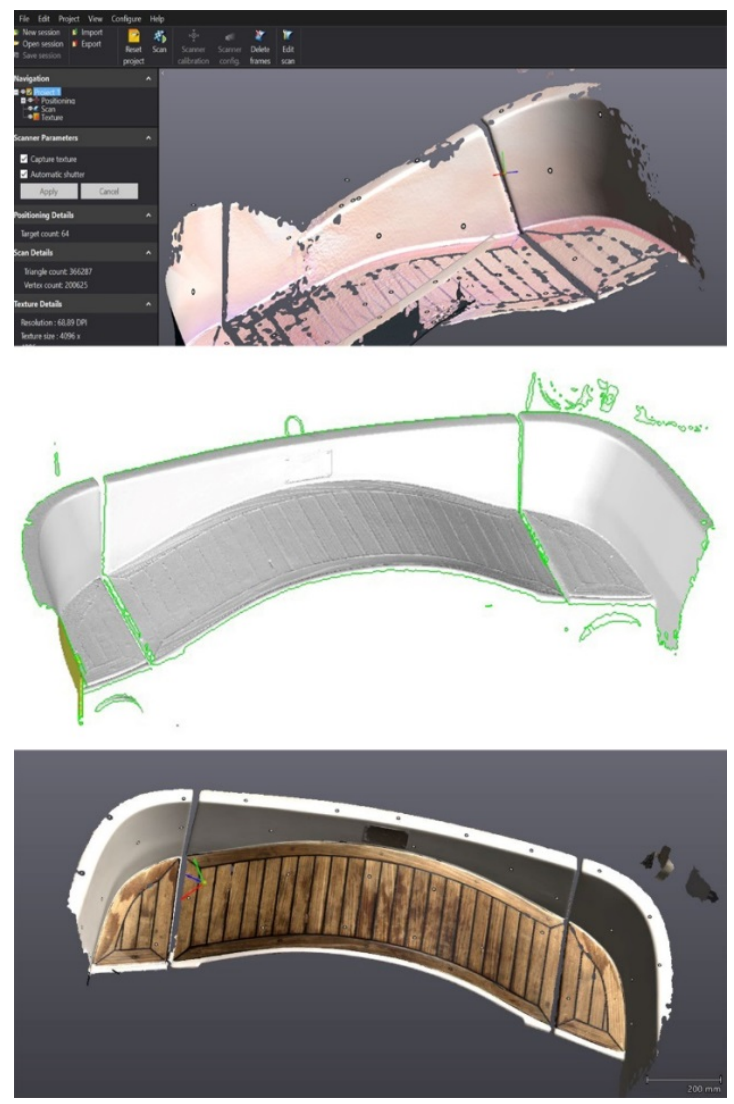

Figure 3. Boat surface scanning by Creaform ScanGo 50.

The survey carried out by the photomodelling technique included a totality of 20 images, loaded in three different dedicated software: Agisoft Photoscan, Visual SfM and Autodesk Remake. Each instrument is different because of its time data processing, difficulty of use, accuracy and precision of results [7]. Furthermore, the proposed applications include both open-source and commercial software.

\section{DATA PROCESSING}

The $3 \mathrm{D}$ data processing is the same for each software: the first operation is the manipulation of the $3 \mathrm{D}$ point cloud. The next step is the creation of three-dimensional model, called "triangulation": starting from the input data vertices, edges and faces are generated. The result obtained is a set of coordinates, which is converted into a polygonal surface [8]-[10]. With editing software as MeshLab and Geomagic Studio, it is possible to perform manual editing of data, merging, scaling, aligning of different surfaces, creating a three-dimensional surface with the aid of different algorithms [11]-[13] (Figure 4, Figure 5, Figure 6).

\section{COMPARISON}

After the alignment process, the research concerned the comparison between the results of photomodelling technique, identified as TEST, and a REFERENCE model. The surface reconstructed by the scanning system has been chosen as reference [14]-[16].
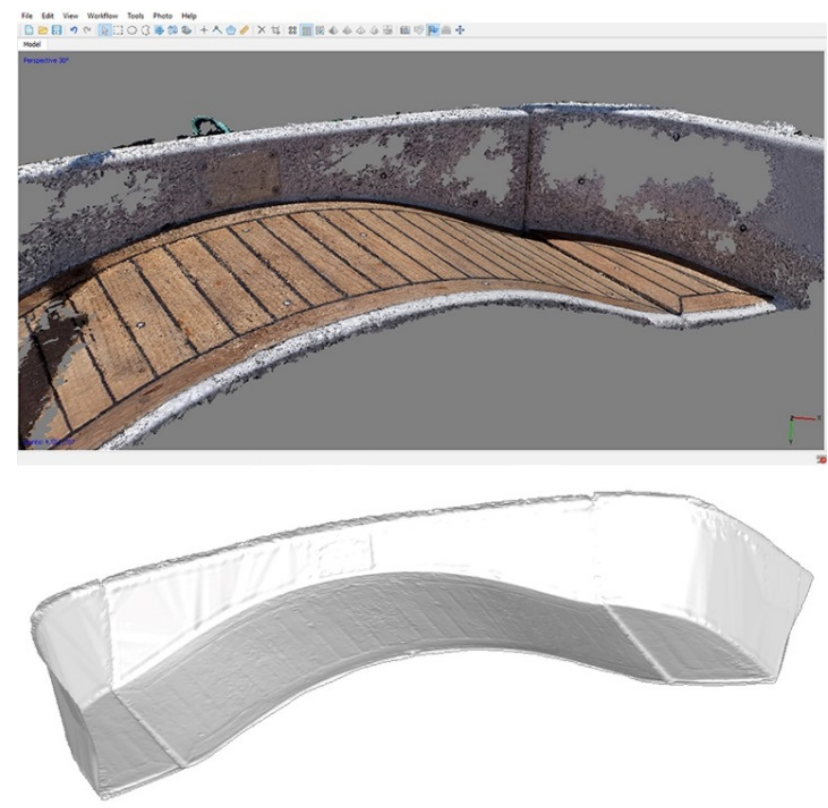

Figure 4. Surface 3D model and point cloud by Agisoft Photoscan.

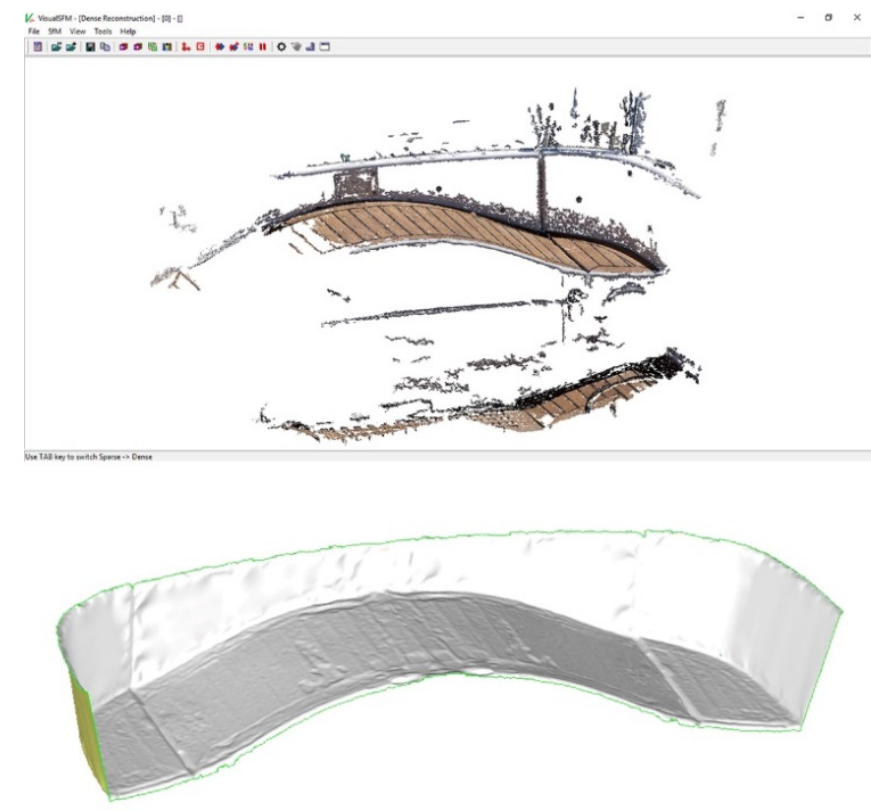

Figure 5. Surface 3D model and point cloud by Visual SfM. 

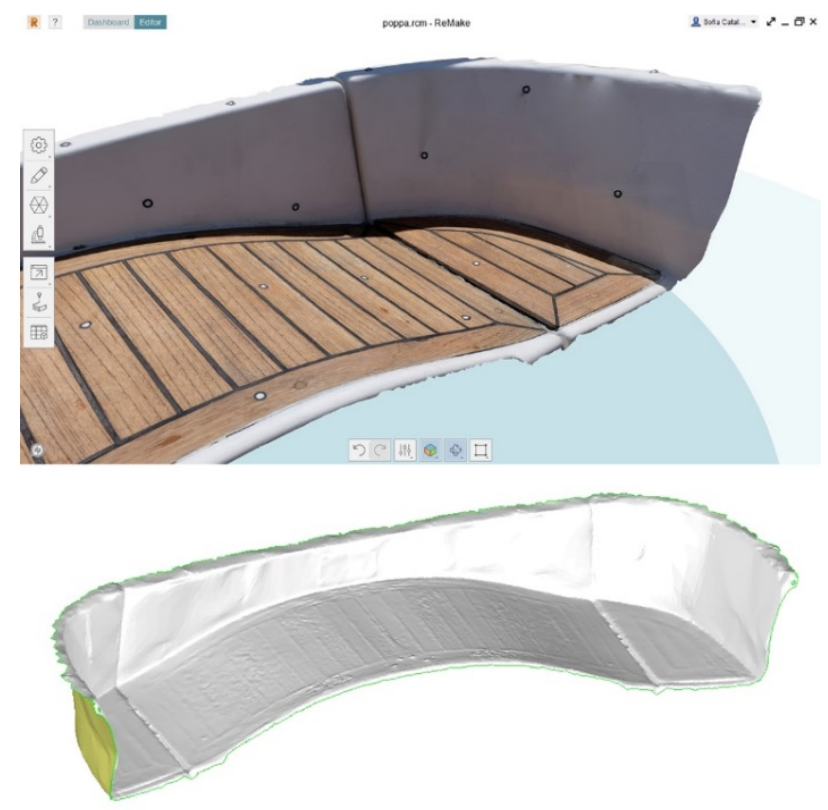

Figure 6. Surface 3D model by Autodesk Remake.

The software chosen for the comparison is Geomagic Qualify. The comparison has been made using algorithms that provide variances and deviations between geometric entities in the space and it had as output $2 \mathrm{D}$ and $3 \mathrm{D}$ maps of such deviations. It was possible to derive a matrix in .CSV format of the test and reference points spatial coordinates $x, y, z$ and of the values of the mutual distances for each pair of points.

After the manual and automatic alignment process, a spectrum of 15 intervals of values has been set: -10 and +10 $\mathrm{mm}$ deviation is the range of acceptability; the range between -1 and $+1 \mathrm{~mm}$ is the optimum correspondence between the test and reference points.

As it is clear from the various elaborate graphs, the best result is the comparison with the TEST model of Agisoft Photoscan
(Table 1, Figure 7). The results obtained with Visual SfM are close to the previous ones (Table 1, Figure 8). On the contrary, Autodesk Remake highlights the differences in terms of precision and accuracy of both the previously mentioned software programs, especially the second one. Autodesk Remake is a simple software, which can be used by every kind

Max +/- : $54.381 /-63.689 \mathrm{~mm}$

Average $+/-: 2.652$ / $-3.080 \mathrm{~mm}$

Mean value of the distance between TEST/REFERENCE models:- $0.27303 \mathrm{~mm}$ Standard Deviation: $3.9393 \mathrm{~mm}$

Mean value of all differences +/- devstd: $(3.6663,-4.2124) \mathrm{mm}$

Number of measured points: 249761

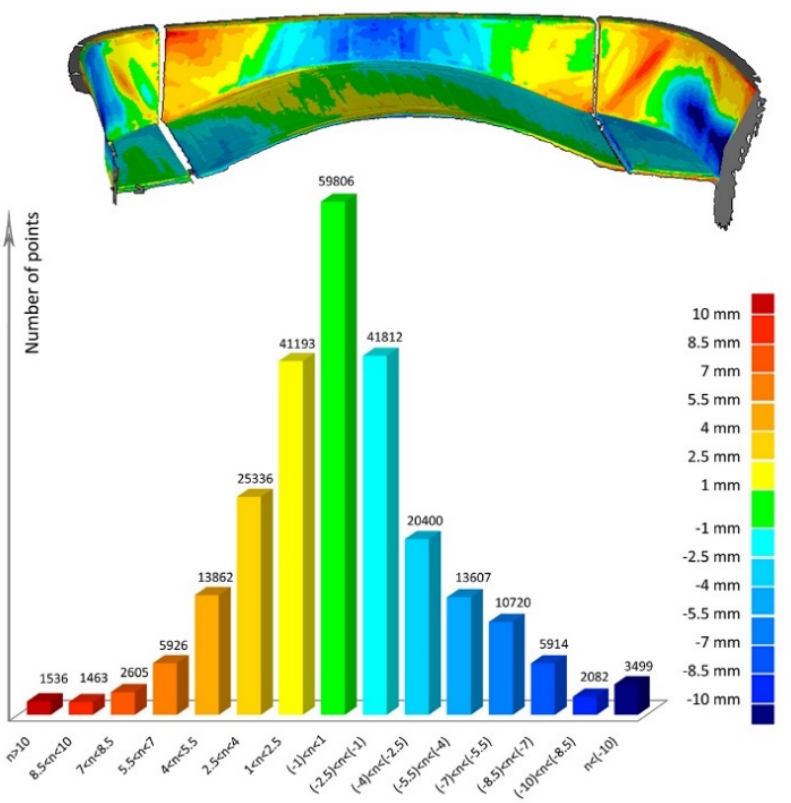

Figure 7. Maps of deviation distribution (Agisoft Photoscan).

Table 1. Deviation distributions

\begin{tabular}{|c|c|c|c|}
\hline Deviation distribution range & $\begin{array}{l}\text { Agisoft Photoscan } \\
\text { Number of points }\end{array}$ & $\begin{array}{c}\text { Visual SfM } \\
\text { Number of points }\end{array}$ & $\begin{array}{l}\text { Autodesk Remake } \\
\text { Number of points }\end{array}$ \\
\hline$n>10$ & 1536 & 1550 & 10136 \\
\hline $8.5<n<10$ & 1463 & 1802 & 2956 \\
\hline $7<n<8.5$ & 2605 & 2400 & 2745 \\
\hline $5.5<n<7$ & 5926 & 4144 & 2526 \\
\hline $4<n<5.5$ & 13862 & 8631 & 3104 \\
\hline $2.5<n<4$ & 25336 & 40056 & 3367 \\
\hline $1<n<2.5$ & 41193 & 73095 & 3837 \\
\hline$(-1)<n<1$ & 59806 & 74819 & 4168 \\
\hline$(-2.5)<n<(-1)$ & 41812 & 28267 & 3118 \\
\hline$(-4)<n<(-2.5)$ & 20400 & 19176 & 3924 \\
\hline$(-5.5)<n<(-4)$ & 13607 & 10287 & 4520 \\
\hline$(-7)<n<(-5.5)$ & 10720 & 6002 & 5298 \\
\hline$(-8.5)<n<(-7)$ & 5914 & 5847 & 5873 \\
\hline$(-10)<n<(-8.5)$ & 2082 & 6623 & 4188 \\
\hline $\mathrm{n}<(-10)$ & 3499 & 23918 & 13311 \\
\hline$n>10$ & 1536 & 1550 & 10136 \\
\hline $8.5<n<10$ & 1463 & 1802 & 2956 \\
\hline $7<n<8.5$ & 2605 & 2400 & 2745 \\
\hline $5.5<n<7$ & 5926 & 4144 & 2526 \\
\hline $4<n<5.5$ & 13862 & 8631 & 3104 \\
\hline $2.5<n<4$ & 25336 & 40056 & 3367 \\
\hline $1<n<2.5$ & 41193 & 73095 & 3837 \\
\hline$(-1)<n<1$ & 59806 & 74819 & 4168 \\
\hline
\end{tabular}


Max +/- : $51.380 /-22.958 \mathrm{~mm}$

Average $+/-: 2.271 /-4.750 \mathrm{~mm}$

Mean value of the distance between TEST/REFERENCE models:- $0.81653 \mathrm{~mm}$ Standard Deviation: $4.9616 \mathrm{~mm}$

Mean value of all differences +/- devstd:(4.1451,-5.7781) mm

Number of measured points: 306617

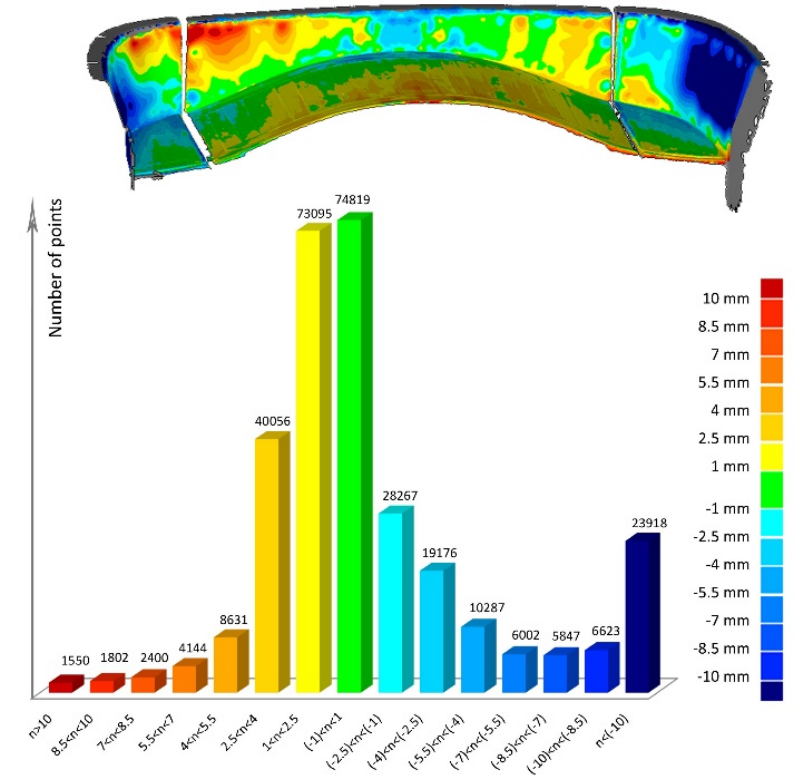

Figure 8. Maps of deviation distribution (Visual SfM).

of users, and it does not elaborate significant results (Table 1, Figure 9). After the comparison, the next step is to upload the data into MATLAB, processing the data in histograms of frequency, absolute values of deviations and curves of probability density (Table 2, Figure 10).

A "measure" is a range of values, acquired with the purpose of controlling a process, performing the calibration of an instrument or allowing the physical understanding of a partially known phenomenon [17]-[19].

Binding to this assertion, to further support the experimentation, the same obtained 3D models have been imported into the multi-paradigm numerical computing environment MATLAB. Through the elaboration of chromatic maps (Figure 13, Figure 14, Figure 15), which identify the volumetric error distribution and the distance between the closest point-to-surfaces of the meshes composing the models, it has been possible to compare the three-dimensional surfaces through an algorithm. This algorithm is based on a modified function operating through the ICP (Iterative Closest Point) approach, which minimizes the distance between two dispersion of multidimensional points, i.e. the two point clouds to be registered and compared, respectively labelled as Reference Point Cloud (RPC) and Measured Point Cloud (MPC). The algorithm works through an iterative process and its goal is to minimize the value of a global goal function. In this case the global function as been developed as the global volumetric error (GVE), calculated as the sum of volumes of the single prismatic element, as shown in Figure 11.

The approach in terms of volumes instead of the classic point-to-point distance gives an improved information: the value of GVE takes into account the size of the triangulated meshes elements. Flat areas with large mesh size have a larger
Max +/- : $27.726 /-45.905 \mathrm{~mm}$

Average +/- : $7.499 /-7.730 \mathrm{~mm}$

Mean value of the distance between TEST/REFERENCE models: $-1.2971 \mathrm{~mm}$ Standard Deviation: $8.772 \mathrm{~mm}$

Mean value of all differences +/- devstd: $(7.4748,-10.0691) \mathrm{mm}$

Number of measured points: 73071

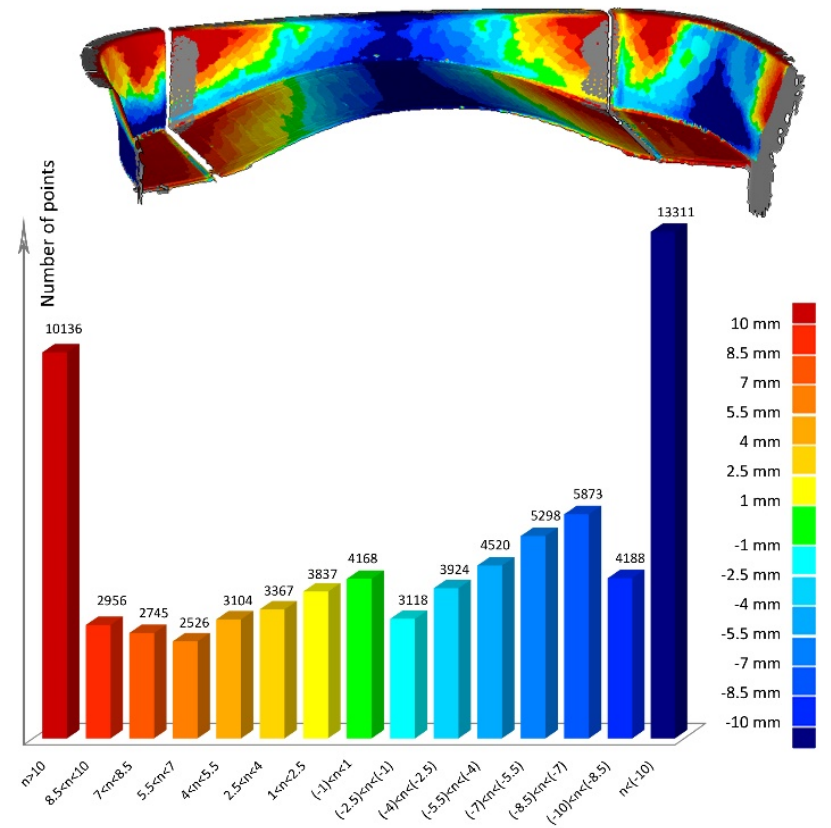

Figure 9. Maps of deviation distribution (Autodesk Remake).

Table 2. Total number of measured points.

$\begin{array}{cc}\text { Agisoft Photoscan } & 249761 \\ \text { Visual SfM } & 306617 \\ \text { Autodesk Remake } & 73071\end{array}$

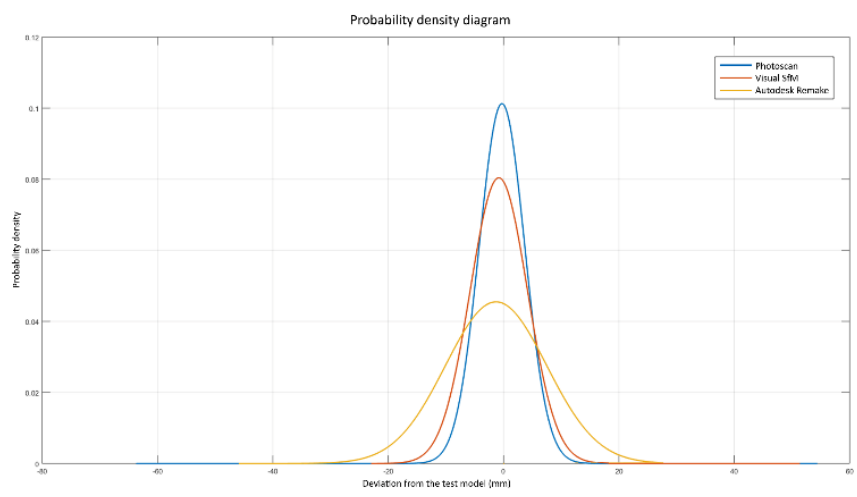

Figure 10. Probability density diagram.

weight than areas characterised by a small mesh size. This behaviour is characteristic of volumetric approaches. For each comparison, the algorithm has elaborated box plot statistical diagrams and volumetric error distribution graphs (Table 3, Figure 12).

It is possible to notice that the volumetric error distribution 
Table 3. Volumetric error distribution.

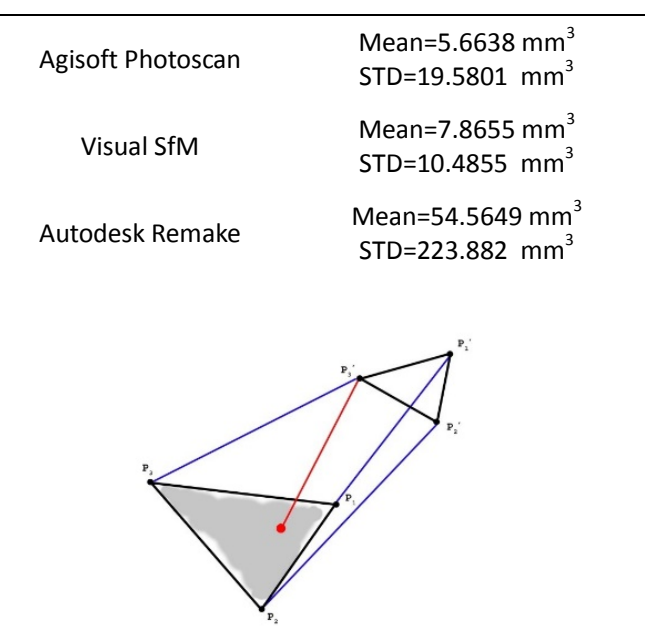

Figure 11. Triangular mesh distance $(\mathrm{mm})$ : ICP function (Iterative Closest Point).

is quite similar to the behaviour of point-to-point approach, due to the high regularity of mesh sizing of both reconstructed surfaces.

\section{CONCLUSIONS}

The paper presents the metrological characteristics of simple and economical photomodelling techniques for boat shape measurements. The surfaces generated by two different

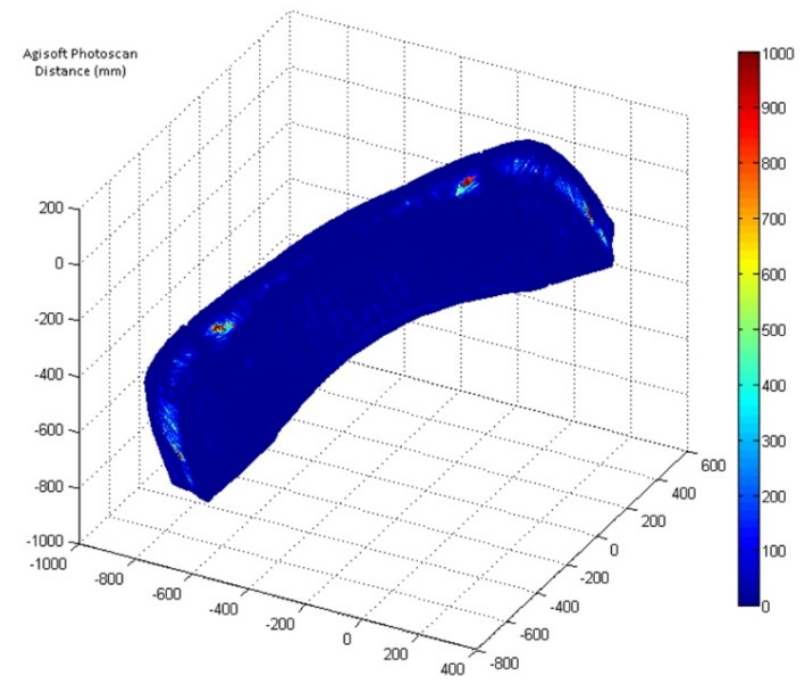

Figure 13. Chromatic maps: Agisoft Photoscan.

techniques as photomodelling and a structured light 3D scanner with metrological certification have been detected in order to investigate the alignment error due to a poor geometry reconstruction. The comparison was made between three photomodelling processes performed by the software Agisoft Photoscan, Visual SfM and Autodesk Remake; the results show different performances, in terms of deviation distributions and volumetric errors. The registration of the measured point clouds and the analysis of the error distribution have been
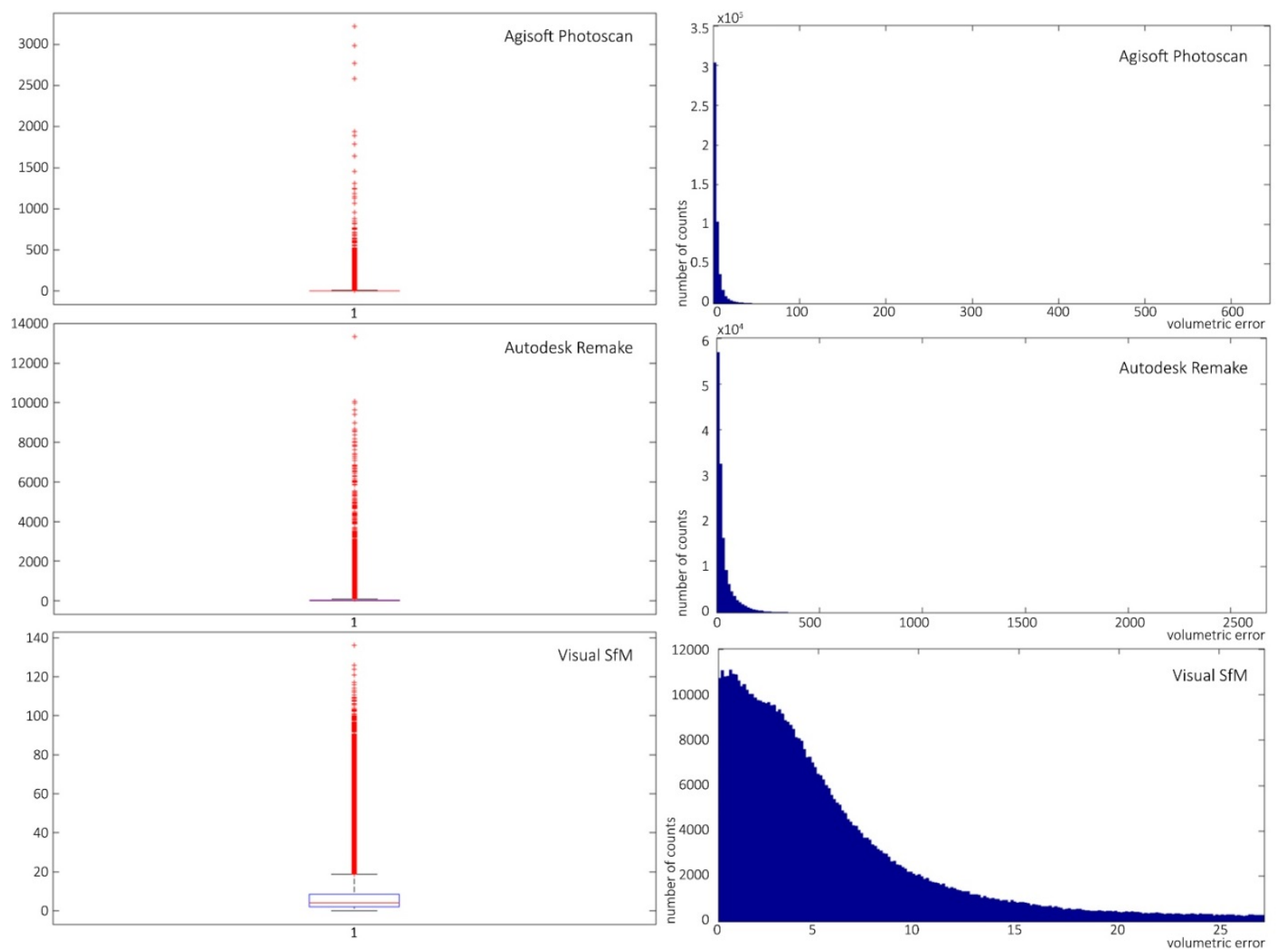

Figure 12. Volumetric error distribution and Box Plot: Agisoft Photoscan, Visual SfM and Autodesk Remake. 


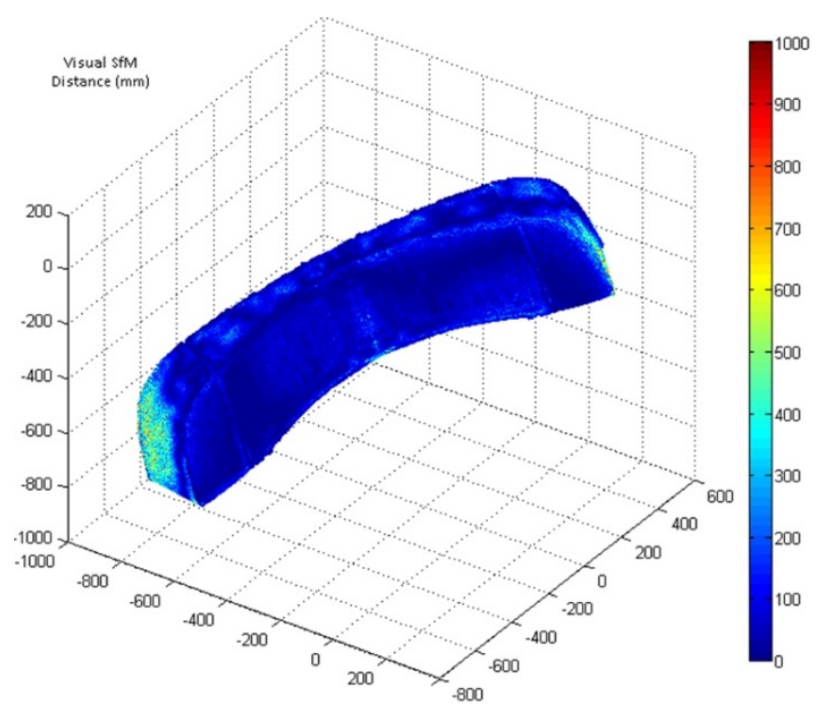

Figure 14. Chromatic maps: Visual SfM.

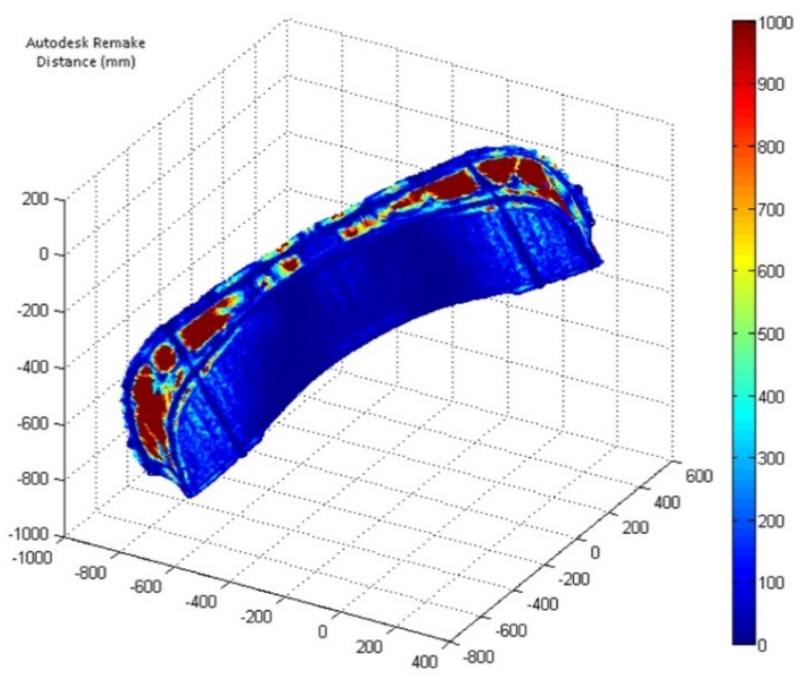

Figure 15. Chromatic maps: Autodesk Remake.

carried out with the commercial software Geomagic Qualify. A tailored software in MATLAB environment has been realised in order to modify the target of registration algorithms through the global volumetric error calculation.

\section{REFERENCES}

[1] L. De Luca, "La fotomodellazione architettonica. Rilievo, modellazione, rappresentazione di edifici a partire da fotografie", Dario Flaccovio Editore, Palermo, 2011, pp.19-30.

[2] M. Filippucci, "Nuvole di pixel. La fotomodellazione con software liberi per il rilievo d'architettura", Disegnarecon, 2010, vol.3(6), pp.50-63.

[3] I.E. De Napoli, E. M. Zanetti, G. Fragomeni, E. Giuzio, A.L. Audenino, G. Catapano, "Transport modeling of convectionenhanced hollow fiber membrane bioreactors for therapeutic applications", Journal of Membrane Science, vol. 471 (2014), p. 347-361, ISSN: 0376-7388, doi: 10.1016/i.memsci.2014.08.026.

[4] E.M. Zanetti, A.L. Audenino; "Differential Thermography for Experimental, Full-field Stress Analysis of Hip Arthroplasty" (2010) J. Mechanics in Med\&Biol., Vol. 10(3), World Scientific Journals, London, UK, pp. 515-529. ISSN: 0219-5194, doi: 10.1142/S0219519410003496.
[5] E. Speranzini, R. Marsili, M. Moretti, G. Rossi, "Image analysis technique for material behavior evaluation in civil structures", Materials, 10 (7) (2017), art. no. 770, doi: 10.3390/ma10070770.

[6] E. Speranzini, S. Tralascia, "Engineered Lumber: LVL and solid wood reinforced with natural fibres", WCTE 2010 - 11th Word Conference on Timber Engineering, 2010, editrice Pergine, Trento, 2, pp. 1685-1690, ISBN: 978-162276175-3, Scopus: 2s2.0-84870414692.

[7] V.A. Girelli, "Tecniche digitali per il rilievo, la modellazione tridimensionale e la rappresentazione nel campo dei Beni Culturali", Tesi Dottorato di ricerca in Scienze Geodetiche e Topografiche, Alma Mater Studiorum Università di Bologna, ciclo XIX.

[8] R. Marsili, A. Garinei, "Thermoelastic Stress Analysis of the Contact Between a Flat Plate and a Cylinder", Measurement: Journal of the International Measurement Confederation, vol.52(1), 2014, pp. 102-110. Available from: http://dx.doi.org/10.1016/j.measurement.2014.03.005

[9] R. Marsili, M. Moretti, G.L. Rossi, "Thermoelastic Modal Stress Analysis", IMAC XXVI Conference \& Exposition on Structural Dynamic, Orlando, Florida USA, 4 - 7 February 2008; ISBN: 0912053984. ISBN 9781605600666

[10] R. Marsili, G. Brustenga, M. Moretti, J. Pirisinu, G.L. Rossi, "Measurement on rotating mechanical component by thermoelasticity", Journal Applied Mechanics and Materials, ISBN 0-87849-987-3 ISSN 1660-9336, Vols 3-4, August 2005, pp 337-342, pp. 411- 416.

[11] M. Kazhdan, M. Bolitho, H. Hoppe, "Poisson Surface Reconstruction”, Eurographics Symp. on Geometry Processing, ed K Polthier and A Sheffer, 2006.

[12] F. Bernardini, J. Mittleman, H. Rushmeier, C. Silva, G. Taubin, "The Ball-Pivoting Algorithm for Surface Reconstruction", IEEE Transactions on Visualization and Computer Graphics, 1999, vol.5(4), pp. 349-359.

[13] R. Marsili, A. Garinei, "Design of an optical measurement system for dynamic testing of electrospindles", in Measurement, 2013, vol.46, Issue 5 (Amsterdam: Elsevier), pp.1715-1721. DOI information: 10.1016/j.measurement.2013.01.006, ISSN: 02632241

[14] J.F. Brouckaert, R. Marsili, G. Rossi, "Development and experimental characterization of a new non contact sensor for blade tip timing", 10th International Conference on Vibration Measurements by Laser and Noncontact Techniques - AIVELA, Ancona, ITALY, JUN 27-29, 2012 Conference Proceedings Volume 1457 Pages: 61 - 68 . DOI: 10.1063/1.4730543 Published: 2012. IDS Number: BBI34. ISSN: 0094-243X. ISBN: 978-0-7354-1059-6.

[15] E. Cardelli, A. Faba, R. Marsili, G. Rossi, R. Tomassini, "Magnetic nondestructive testing of rotor blade tips", Journal of Applied Physics 117 (2015), 17A705; doi: 10.1063/1.4907180.

[16] R. Marsili, A. Garinei, "Development of a new capacitive matrix for a steering wheel's pressure distribution measurement", International Journal of Industrial Ergonomics Volume 44, Issue 1, January 2014, pp. 114-119 doi: 10.1016/j.ergon.2013.11.012.

[17] G. Rossi, "Misure meccaniche e termiche. Basi teoriche e principali sensori e strumenti”, Carocci, Roma, 2010.

[18] M. Becchetti, R. Flori, R. Marsili, M. Moretti, "Comparison between digital image correlation and thermoelasticity for strain field analysis", 9th International Conference on Vibration Measurements by Laser and Noncontact Techniques and Short Course; Ancona; Italy; 22 June 2010 - 25 June 2010 AIP Conference Proceedings, Volume 1253, pp. 233-240, doi=10.1063/1.3455462. ISSN: 0094243X. ISBN: 978073540802-9.

[19] R. Marsili, G.L. Rossi, M. Becchetti, R. Flori, "Stress and strain measurements by image correlation and Thermoelasticity", Society for Experimental Mechanics - SEM Annual Conference and Exposition on Experimental and Applied Mechanics 2009, Volume 1, 2009, Pages 70-75; Albuquerque, NM; United States; 1-4 June 2009; Code 78716; ISBN: 978-161567189-2; 978161567189-2. 